\title{
Preparation and Performance Test of PEFB Reinforced Box Waste Coated Superhydrophobic Coating for Shoe Sole Application
}

\author{
Noraini Marsi ${ }^{1 *}$, Chow Li Kien', Juhari A Rani², Nor Mazlana Main², Mohd \\ Ridzuan Mohd Jamir ${ }^{3}$ and Muhammad Farid Shaari ${ }^{1}$
}

${ }^{1}$ Faculty of Engineering Technology, Universiti Tun Hussein Onn Malaysia (UTHM), Edu Hub Pagoh, KM1, Jalan Panchor, 84600 Pagoh, Johor, MALAYSIA

${ }^{2}$ Tageoronnie Shoe Maker Sdn. Bhd., No.1183, Jalan Sri Putrii 3/3,

Kawasan Perindustrian Taman Putri, 81000 Kulai, Johor, MALAYSIA

${ }^{3}$ School of Mechatronic Engineering,

Universiti Malaysia Perlis (UniMAP), Pauh Putra Campus, 02600 Arau, Perlis, MALAYSIA

*Corresponding Author

DOI: https://doi.org/10.30880/ijie.2020.12.05.026

Received 5 April 2020; Accepted 30 June 2020; Available online 30 June 2020

\begin{abstract}
The study presents preparation and performance test of Palm Empty Fruit Bunches (PEFB) reinforced box waste coated superhydrophobic coating for shoe sole application. The main purpose of this analysis is to determine the optimal composition of PEFB reinforced with box waste for use in shoe soles. In this study, the use of PEFB and box waste is to replace the synthetic materials in the application of the shoe sole. Additionally, environmental problems can be reduced by using waste PEFB as a value-added product rather than biomass waste. Sample preparation involved grinding of PEFB fibers and box waste, blending processes of different PEFB percentages at $20 \%, 40 \%, 60 \%$ and $80 \%$ mixed with $50 \%$ box waste. Followed by the process of mixing with epoxy and hardener, and finally coated with superhydrophobic coating using a spray gun method. Epoxy resin and hardener are used as binders for the bonding between the PEFB fiber matrix and the box waste to be applied to the shoe sole. The study was carried out in both mechanical and physical studies. The test for tensile strength showed $40 \%$ PEFB reinforced with $50 \%$ box waste with $181.36 \mathrm{~N}$ maximum load and $16.70 \%$ of strain. The $40 \%$ PEFB composition showed the optimum bursting pressure to $13.62 \mathrm{kgf}$ and the abrasion resistance had a lower weight loss of $0.28 \mathrm{~g}$. The $80 \%$ higher proportion of PEFB indicates a lower density of $1.06 \mathrm{~g} / \mathrm{cm} 3$ and a higher porosity of up to $0.44 \%$. It is also revealed that $40 \%$ of box waste provided the best composition for the application of the shoe soles.
\end{abstract}

Keywords: box waste, superhydrophobic, shoe sole, PEFB, tensile

\section{Introduction}

The shoe sole is made of synthetic materials such as rubber, thermoplastics, polypropylene, acrylic, composite carbon fibers, thermoform cork, gel, leather, polyethylene foams and others based on end-uses of the footwear [1]. The shoe sole made from synthetic materials produced a huge amount of carbon dioxide during its production but also pose risk to human health. Since synthetic materials are basically non-biodegradable and non-renewable, hence scientists 
nowadays have changed their focus on finding sustainable and green materials such as coconut husk, palm empty fruit bunches (PEFB), agricultural waste and others which have the potential to substitute those synthetic materials.

PEFB fiber is a type of natural fiber that comes from a plant tree which is available in abundance amount as agricultural solid waste in Malaysia. The sustainable, non-hazardous, non-carcinogenic, eco-friendly, biodegradable product that exploited from PEFB fibers surely brings profit to the humankind that widely spread all over the world [2]. Box waste which generally known as the recycled paper box is the main packaging waste that not readily biodegrade in modern landfills but buried to decompose faster. Hence, the good way to solve the box waste is to recycle and reproduce into new products, it saved up usage of water and landfill space, less air pollution during production, addition reduce cut down trees problem [3].

\subsection{Superhydrophobic coating}

The superhydrophobic coating is a nanoscopic surface layer that exhibits extraordinary high repellence against waster. Water droplets that hit on any surface with this kind of coating can bead up and fully rebound in its original shape without being absorbed. The water droplet can be rolling with slight applied force and bouncing if dropped on the surface from a height. In a superhydrophobic surface, the surface morphology plays a crucial role in effecting wettability. Roughening a surface not only enhance its hydrophobicity due to the increase in the solid-liquid interface [4] but also when air can be trapped on a rough surface between the surface and the liquid droplet. Since air is a hydrophobic material with a contact angle of $180^{\circ}$, this air-trapping will amplify surface hydrophobicity [5].

Surface wetting behavior can generally be broken into 4 different regimes, based on the value of water contact angle (WCA). The two most conventional regimes are the hydrophilic and hydrophobic regimes, defined as WCAs in the range of $10^{\circ}<\theta<90^{\circ}$ and $90^{\circ}<\theta<150^{\circ}$, respectively. Superhydrophilicity, which is characterized by WCAs in the range $\theta<10^{\circ}$, within 1 second of the initial wetting, describes nearly perfect wetting. In contrast, superhydrophobicity, described by WCAs of $\theta>150^{\circ}$, describes a state of nearly perfect non-wetting as shown in Figure 1 [6].

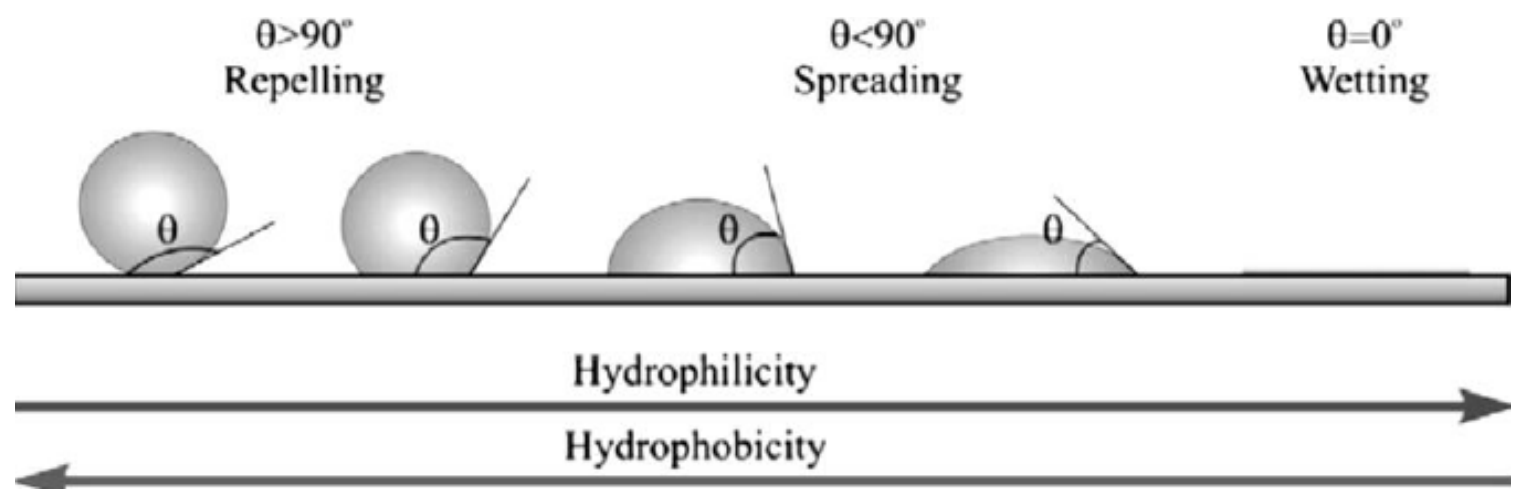

Fig. 1 - Schematic of contact angle for a water drop placed on surfaces of different hydrophobicity [6].

\section{Methodology}

Four samples of shoe sole were prepared with different compositions of PEFB fibers reinforced box waste as shown in Table 1. First, any contaminants, such as sand and glue, were cleaned from PEFB fibers and box wastes. Then, for easier grinding process, PEFB fibers and box wastes were chopped using a grinding machines. The chopped PEFB fibers and box waste were then ground using grinder machine DF-15 Jooshun Model into nearly $20 \mu \mathrm{m}$ powder with a speed of $3450 \mathrm{rpm}$, approximately. Based on the different percentages of composition the ground PEFB fibers and ground box wastes were mixed together using a dry mill. The aluminum mold was cleaned and a layer of silicone spray lubricant onto the surface to act as a mild releasing agent. The mold with a fixed thickness of $3 \mathrm{~mm}$ is then pressed and sandwiched between two other aluminum molds. Then, locked with screws in eight directions and cured for 24 hours at room temperature. Using scrapper and hammer, the shoe sole sample was taken out after one day. Figure 2 showed prepared shoe sole samples.

Table 1 - The different composition of PEFB

\begin{tabular}{|c|c|c|c|}
\hline Samples & PEFB fiber (\%) & Box wastes (\%) & Ratio of epoxy resin: hardener \\
\hline A & 20 & 50 & $3: 1$ \\
\hline B & 40 & 50 & $3: 1$ \\
\hline C & 60 & 50 & $3: 1$ \\
\hline D & 80 & 50 & $3: 1$ \\
\hline
\end{tabular}



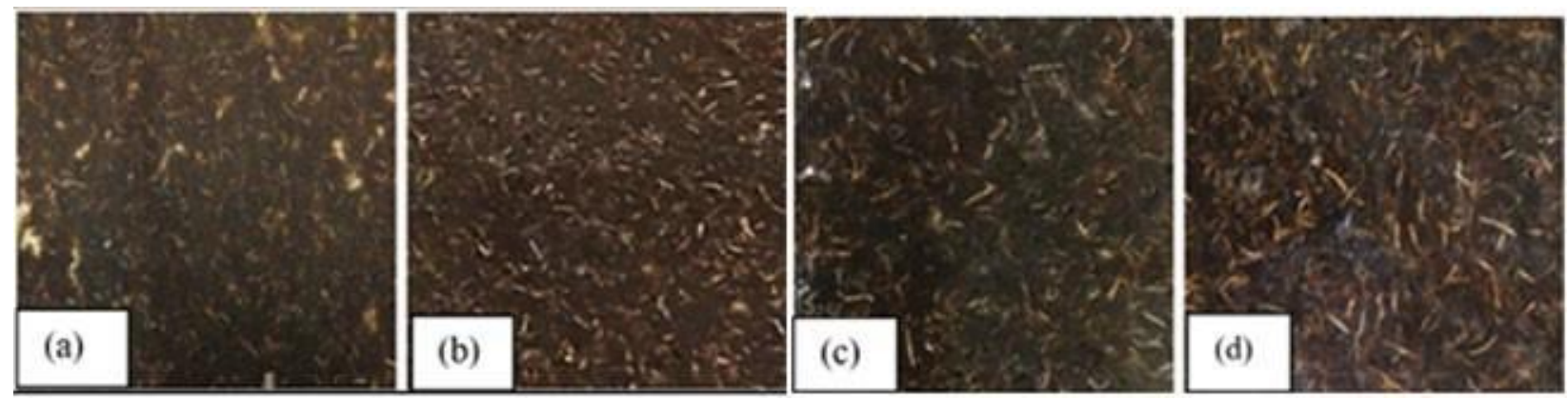

Fig. 2 - Shoe sole sample with different percenatges of PEFB (a) 20\%; (b) $40 \%$; (c) 60\%; (d) $80 \%$ reinforced with $50 \%$ box waste

The solution of superhydrophobic coating is required to coated shoe sole surface protecting it from any dirt. The components are the important parts of the superhydrophobic coating solution. The solvent and hardener were using for a mixture of the superhydrophobic coating solutions. The ratio for the solvent to hardener in this study is $3: 1$. In a beaker, the magnetic stirrer is used to mix solvent, hardener and additive to ensure that the solutions are well mixed. The mixed solution is sprayed by using a spray gun method and sprayed uniformly onto the surfaces of shoe sole samples at $0.2-0.3 \mathrm{MPa}$, a distance of $25 \mathrm{~cm}$ between the nozzle and sample with a spray angle of $45^{\circ}$. The transparent coatings are deposited onto the sample and transfer of the water droplet from the dispenser syringe to the sample surfaces as shown in Figure 3.

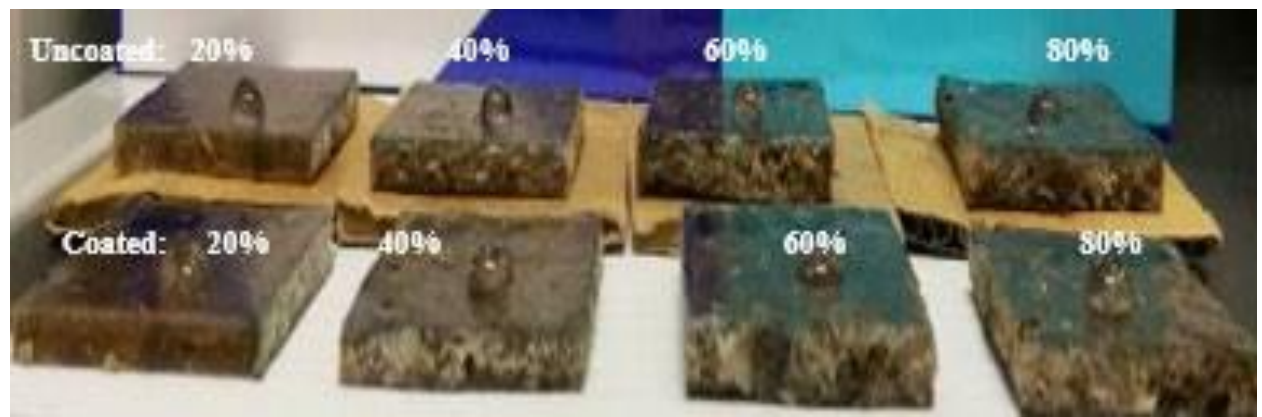

Fig. 3 - The sample of shoe sole uncoated and coated of super hydrophobic coating with different percentages of PEFB

\section{Results and discussions}

\subsection{Tensile strength}

The tensile strength test of ASTM D5083-17 was conducted to measure the strength of the samples that is stretched in unidirectional which is normally in a length direction. The tensile strength test was measured with the Universal Testing Machine, model no. LR 30KPlus Lloyd Instruments LTD. The samples are prepared by cutting into a rectangular dimension of $250 \mathrm{~mm}$ in length and $25 \mathrm{~mm}$ in width. The load was applied at a continuous speed of $5 \mathrm{~mm}$ per minute. The force of the load cell was set at maximum-till $500 \mathrm{~N}$ and minimum till $10 \mathrm{~N}$. The maximum value of the tension load was known when the specimen broken into two pieces during an experimental test run. Figure 4 exhibited the graph of load versus time for different percentages of PEFB. It is clearly exhibited that $40 \%$ of PEFB withstand the higher maximum load value of $181.36 \mathrm{~N}$, followed by $60 \%$ of PEFB with a value of $124.84 \mathrm{~N}$, then $20 \%$ of PEFB with a value of $104.68 \mathrm{~N}$ and lastly $80 \%$ of PEFB which can hold up till value of $70.00 \mathrm{~N}$. Tensile properties of composite material are mainly depending on fiber strength, modulus, fillers, fiber length and orientation, fiber-matrix interfacial bonding, and fiber content [7]. Sreekala, M. S., \& Thomas, S. (2018) was investigated the tensile properties of the utilization of short PEFB fiber as a reinforcement in phenol-formaldehyde resins. It is summarized that at a higher percentage of fiber as reinforcement, there is an opportunity of phase separation and agglomeration of fibers, hence reducing the effective aspect ratio. At higher percentage of fiber in the sample, the fiber-fiber contact increases but the fiber-matrix adhesion decreases, which leads to a weak interfacial bond of fiber-matrix and resulting in inefficient load transfer [8].

Figure 5 summarized the stress-strain behavior of each sample. At the early stage, four linearity of elastic deformation and thereafter four curvatures of plastic deformation are observed. As the applied stress increases, the 
epoxy is being stretched out, subsequently, the box waste being torn apart and left the opening of PEFB fibers in the air to pull out from matrix till broken. Then, the weak primary cell wall of PEFB fiber collapses and the decohesion of cells occurs, resulting in the mechanical failure of the fiber [9]. 20\% of PEFB had a higher percentage strain of 39.50\%, it might properly due to strong cohesion bonding of matrix bonding. Followed by $40 \%$ of PEFB had percentages strain of $16.71 \%$, then $80 \%$ of PEFB had percentages strain of $16.20 \%$ and lastly, $60 \%$ of PEFB had percentages strain of $8.20 \%$. Figure 6 exhibited the tensile strength result. It is clearly exhibited that $40 \%$ of PEFB withstand the higher tensile strength value of $2.20 \mathrm{MPa}$, followed by $60 \%$ of PEFB with a value of $1.96 \mathrm{MPa}$, then $20 \%$ of PEFB with a value of $1.42 \mathrm{MPa}$ and lastly $80 \%$ of PEFB which can hold up till value of $1.27 \mathrm{MPa}$. The maximum tensile strength for both polylactic acid-PEFB and polystyrene-PEFB was recorded at $40 \%$ of PEFB, which exhibited a value of $58.9 \mathrm{MPa}$ and 17.6 $\mathrm{MPa}$ respectively. The strength of the composites started to deteriorate with further increase fiber percentage at $60 \%$ of PEFB. This is supported by previous studies that at volume fraction greater than $50 \%$, the fibers tend to aggregate in the composite which weakens the interfacial area and debonding tends to take place between the fibers and matrix [10].

For previous research, Ngo, W. L., Pang, M. M., Yong, L. C., \& Tshai, K. Y. (2014) had studied the tensile properties of PEFB fiber reinforced polymer composites. Bursting strength test (ASTM D3786M-13) was conducted to measure the strength in which the sample is given pressure in all directions at the same time using diaphragm bursting strength tester. The samples are prepared by cutting into a circular shape of rubber diaphragm which is $80 \mathrm{~mm}$ in diameter. The burst test was performed by the expansion of hydraulic pressure applied onto the rubber diaphragm at a gradually increasing rate to extend and stretch the sample until rupture. Generally, bursting strength depends upon the type, ratio, and amount of fibers present in the sample, their method of preparation, their degree of blending and refining, upon sample formation, and the use of additives. Based on Figure 7, the bursting strength increases as the percentage of PEFB increases at the same time. Sample of $80 \%$ PEFB had withstood the highest bursting strength of $59.74 \mathrm{kPa}$ while the lowest bursting strength is $36.17 \mathrm{kPa}$ falls on a sample of $20 \%$ PEFB. The bursting strength increases as the number of fiber increases, this is due to the agglomeration of fiber-enhanced the strength of the material from being burst out. The bursting strength is highly dependent upon fiber-to-fiber bonding instead of fibermatrix bonding [11]. Hence, for the higher fiber loading, there is a chance that the agglomeration of fiber can enhance the fiber-to-fiber bonding.

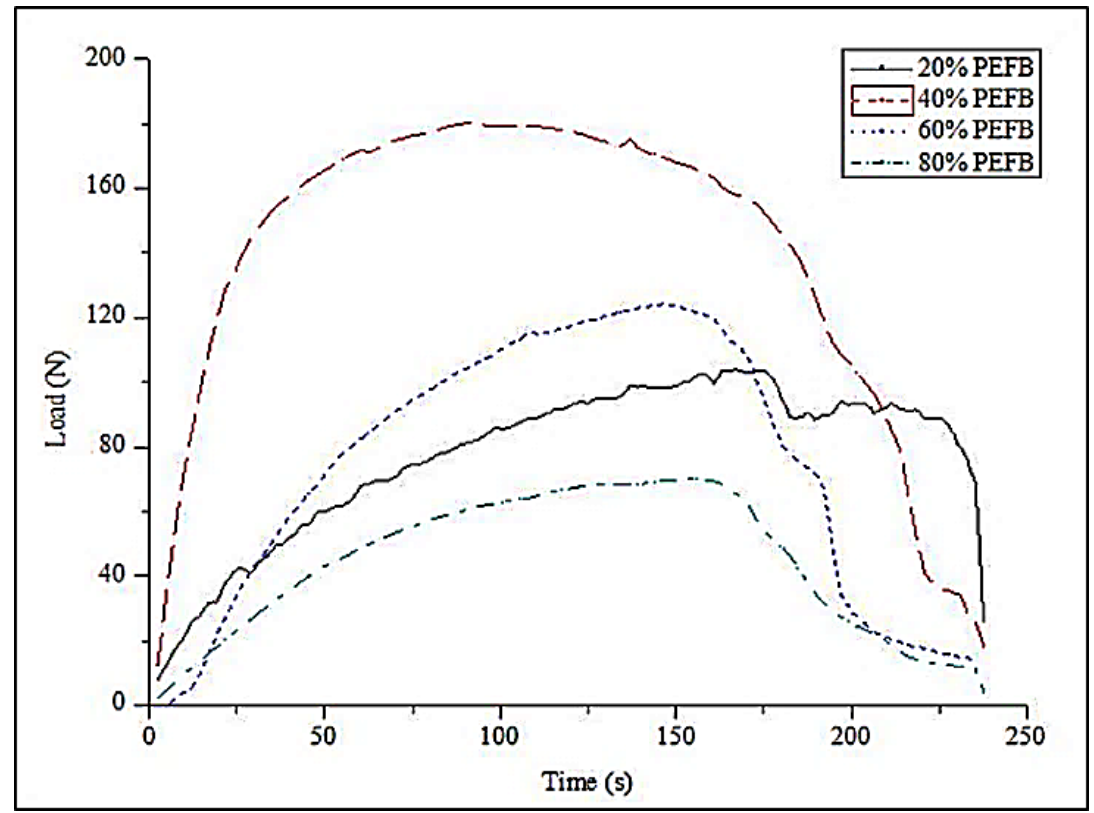

Fig. 4 - Load versus time at different percentages of PEFB. 


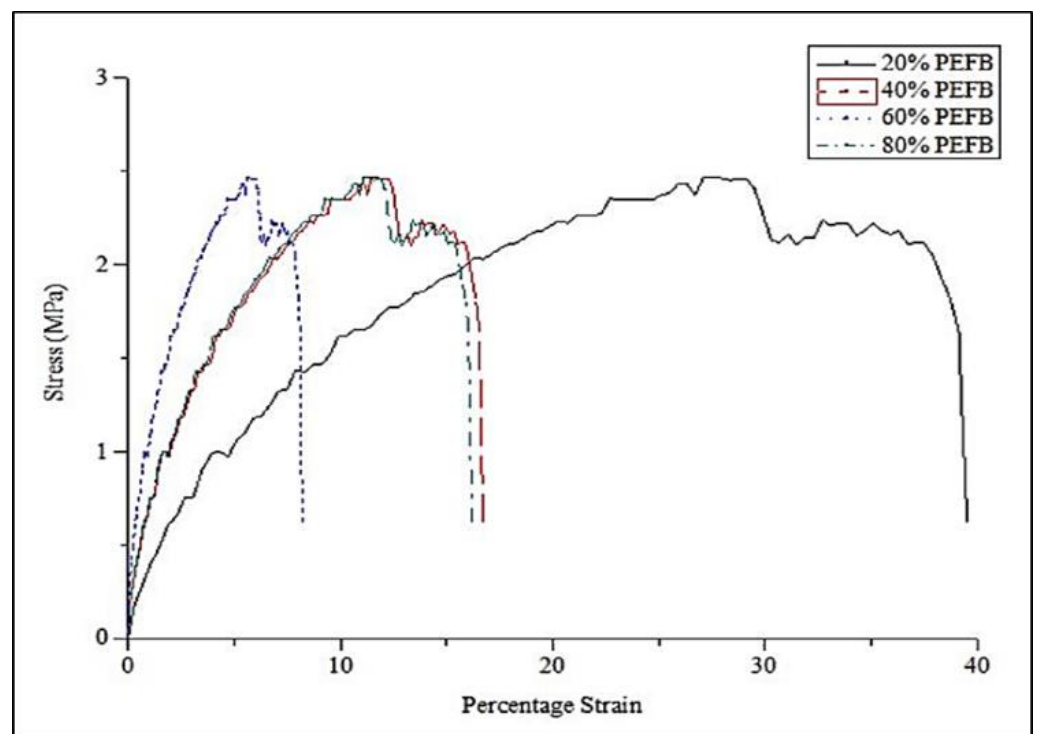

Fig. 5 - Load versus time at different percentages of PEFB.

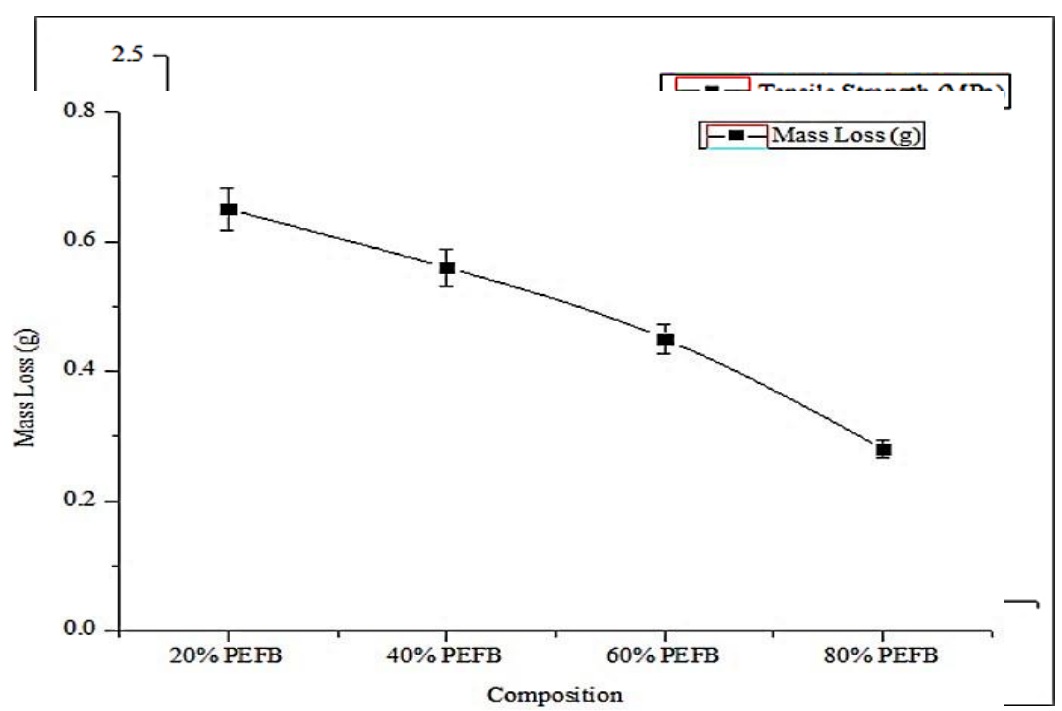

Fig. 6 - Tensile strength results at different of PEFB.

\subsection{Abrasion Resistance Test}

Abrasion resistance test (ASTM D4966-12) was conducted to measure the durability of a material to hold out against mechanical action such as rubbing and scraping toward the surface. The samples are prepared by cutting into a diameter of $38 \mathrm{~mm}$. The sample is fixed on the sample holder. Besides, for the preparation of abrasive material, 4 pieces of the abrasive papers are cut, the diameter of each piece is $140 \mathrm{~mm}$. The Martindale abrasion tester is used and run until the sample is wear and tear. The experiment is repeated for 100, 250, 500, 750 and 1000 number of rubbing. Bursting strength results shows the higher percentages of PEFB produce a higher bursting strength up to $60 \mathrm{kPa}$ as shown in Figure 7. Figure 8 showed the mass loss result after 1000 rubs at a different percentages of PEFB. The mass loss decreases as the composition of PEFB fiber increases. 20\% of PEFB have a higher mass loss of $0.65 \mathrm{~g}$ after 1000 number of rubbing, while $80 \%$ of PEFB have a lower mass loss of $0.28 \mathrm{~g}$. $20 \%$ of PEFB indicated that there is more amount of matrix in the sample. More and more matrix debris was coming out on the fabric surface and torn apart from the surface due to the number of rubbing is increasing.

Figure 9 showed the cumulative mass loss result after 100, 250, 500, 750 and 1000 numbers of rubbing. After the 100 times of rubbing, there is $0.13 \mathrm{~g}$ of mass loss changes from $20 \%$ of PEFB, remain constant to $40 \%$ PEFB, then decreases to $0.08 \mathrm{~g}$ for $60 \%$ PEFB and drops again to $0.04 \mathrm{~g}$ of mass loss in $80 \%$ of PEFB. For 250 times, 500 times, 750 times and 1000 times of rubbing, the result of mass loss is similar which shown a decreasing trend from $20 \%$ of PEFB to $80 \%$ of PEFB. It revealed that is a relationship between fiber loading with abrasion loss, the fiber loading is one of the main criteria that affect most of abrasion resistance [12-13]. In the transversely oriented case, the matrix that presents between the fibers is protected against counter face interaction, resulting in a low wear rate. In the longitudinally oriented case, abrasive debris of matrix present between the fibers is easily swept away by the counter face interaction, resulting in high abrasion mass loss [13-15]. 


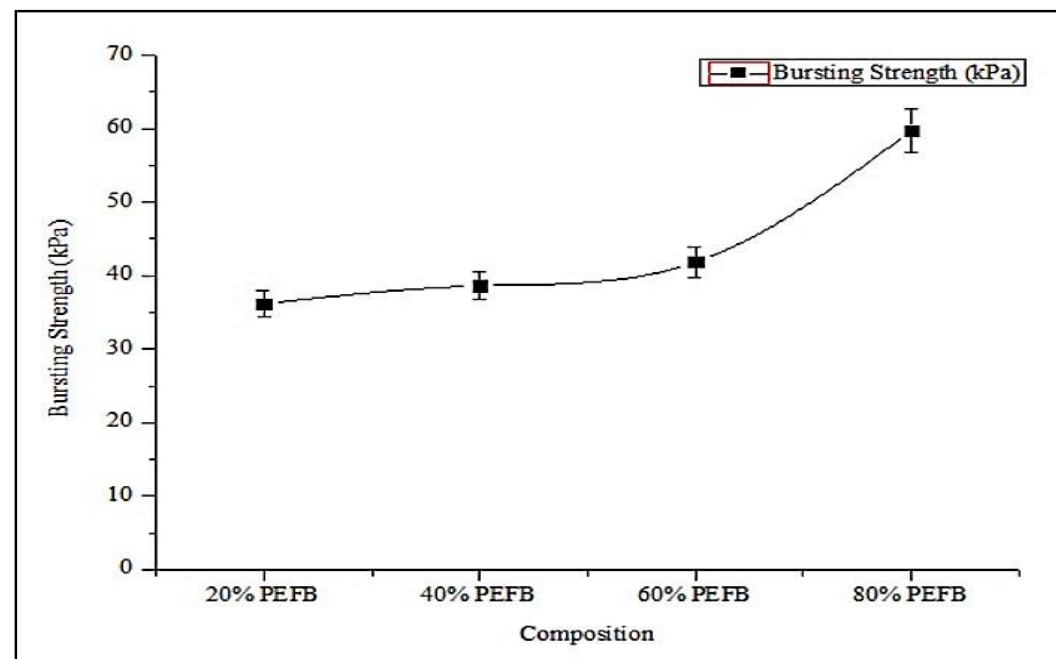

Fig. 7 - Bursting strength results at different percentages of PEFB.

Fig. 8 - Mass loss results after 1000 number of rubbing at different percentages of PEFB

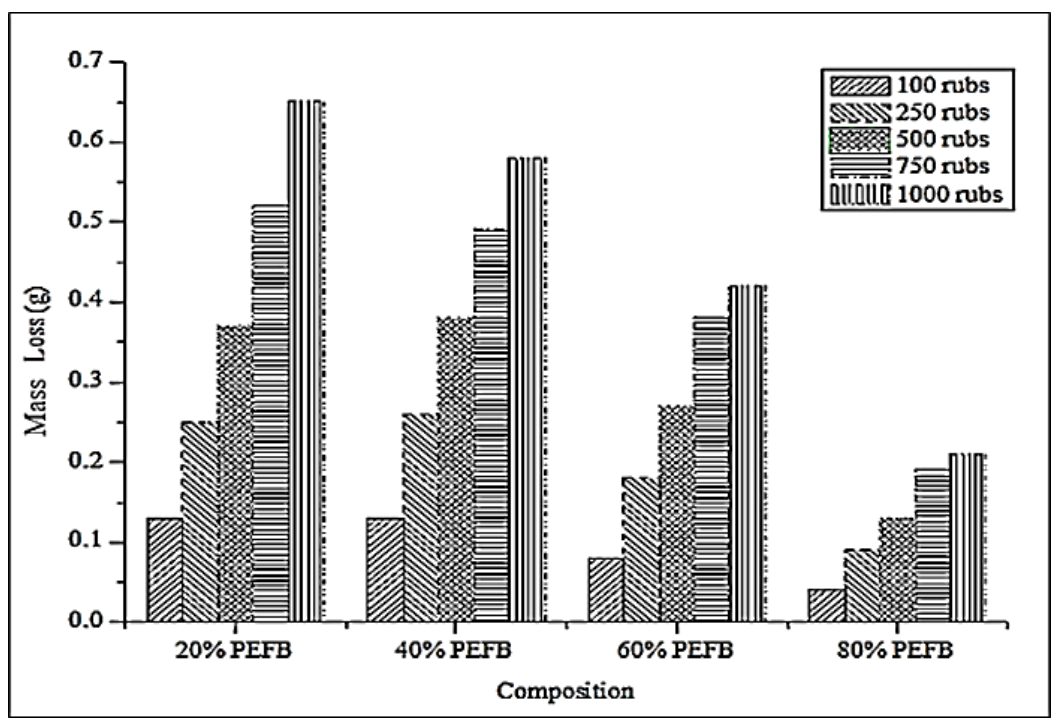

Fig. 9 - Cumulative mass loss versus different number of rubs at different percentages of $\mathrm{PE}$ 


\section{Conclusion}

In conclusion, the optimum composition percentage of PEFB fibers in $60 \%$ reinforced with $50 \%$ box waste is possible to be applied for shoe sole application. The mechanical and physical tests based on the different percentages of PEFB reinforced with box waste for shoe sole application had been evaluated. The maximum tensile strength was observed at $40 \%$ PEFB fiber loading with $181.36 \mathrm{~N}$ and a percentage strain of $16.70 \%$. There is a possibility of PEFB fiber entanglement at higher fiber loadings which may be the reason for the decrease in tensile strength beyond $40 \%$. The bursting strength showed linear enhancement with an increase in fiber loading up to 80\%. The abrasion mass loss shown the decreasing trend with the increase of PEFB fiber loading, it revealed again $80 \%$ PEFB fiber resisted abrasion wear. However, for the best balance of mechanical properties, the optimum composition of PEFB fiber is $40 \%$. Thus, PEFB reinforced with box waste is applicable for shoe sole application. The utilization of PEFB fiber and box waste for shoe sole application will eliminate the environmental problem of waste disposal and will lead to a new added-value product.

\section{Acknowledgement}

The authors would like to thank the Universiti Tun Hussein Onn Malaysia for supporting this project under GPPS Grant by UTHM Scheme under Vot H340.

\section{References}

[1] A. Kushairi, R. Singh and M. Ong-Abdullah "The oil plam industry in Malaysia: Thriving with transformative Technologies". Jounal of Oil Palm Research, vol. 29, 2017, pp. 431-439.

[2] M. F. Othaman, S. Sulastri and M. F. M. Batcha "Emission studies from combustion of empty fruit bunch pellets in a fluidized bed combustor" IOP Conf. Series: Materials Science and Engineering 226 012003, 2017, pp. vol. 12 (14), 2017, pp. 1-9.

[3] N. Marsi, A.Z.M. Rus, Ibrahim, M.R., Samsuddin, S.A., Abdul Rashid, A.H. "The synthesis and surface properties of newly eco-resin based coconut oil for superhydrophobic coating", Solid State Phenomena". Trans Tech Publications, volume 266, 2017, pp.59-63.

[4] A. A. Kadir and S.S.S.Z. Abidin "Solid waste composition and Qualification at Taman Melewar, Parit Raja, Batu Pahat" IOP Conf. Series: Materials Science and Engineering 136 012047, 2015, pp. 1-7.

[5] Fodzi, M.H.M., Marsi, N. and Li Kien, C "Utilization of PEFB reinforced box waste coated super-hydrophobic coating for shoe sole applications" International Journal of Advanced Trends in Computer Science and Engineering 9, vol.75, pp.461-465.

[6] M. S. Sreekala and S. Thomas. "Utilization of short oil palm empty fruit bunch fiber (OPEFB) as a reinforcement in phenol-formaldehyde resins: studies on mechanical properties" Journal of Polymer Engineering, vol.16(4), 1996 , pp. 265 - 294.

[7] M. S. Md Noh "Axial compression behavior of full-scale prefabricated wood-wool wall panel" International Journal of Integrated Engineering, vol. 12 (1), 2020, pp.280-288.

[8] W. L. Ngo, M. M. Pang, L.C. Yong and K. Y. Tsai "Mechanical properties of natural fibre (kenaf, oil palm empty fruit bunch) reinforced polymer composites" Advances in Environmental Biology, American-Eurasian Network for Scientific Information. vol.8(8), 2014, pp. 2742-2747.

[9] A. R. Azrin Hani, N. S. Azman, R. Ahmad, M. Mariatti, M. N. Roslan and N. Marsi "Ballistic impact response of woven hybrid coir/Kevlar laminated composites" MATEC Web of Conferences. Vol 78(7), 01048, 2016, pp. 1-7.

[10] N. Zainal, H.H. Arifin, L. Zardasti, N. Yahaya, K.S. Lim and N.M. Noor "Mechanical properties of Graphenemodified epoxy grout for pipeline composite repair" International Journal of Integrated Engineering. Vol.10(4), 2018, pp.176-184.

[11] T. N. Kumar, A. Megalingam and M. Kalidass "Experimental analysis of fracture toughness of sisal/borasus polyester fiber reinforced composite", Advance Science Letter. Vol .22, 2016, pp.60-63.

[12] F. Liu, S. Deng and J. Zhang "Mechanical properties of epoxy and its carbon fiber composites modified by nanoparticles", Journal of Nanomaterials, Hindawi. Vol.2017(8146248), 2017, pp.1-9.

[13] G. Vikas and M. Sudheer "A review on properties of ballast fiber reinforced polymer composites", American Journal of Materials Science. Vol.7(5), 2017, pp.156-165.

[14] N. Marsi and A.Z.M. Rus, 'The Effects of Biopolymers Composite based Waste Cooking Oil and Titanium Dioxide Fillers as Superhydrophobic Coatings', IOP Conference Series: Materials Science and Engineering, 22(1), 012161, pp. 1-9.

[15] A.U. Patwari, S.A. Bhuiyan, Q. Ahsan, I.H., Khan and N.H. Khan, "Prediction and optimization of compressive load of a green composite material from natural fiber using statistical approach", International Journal of Integrated Engineering, vol.11(7), pp.83-89. 